\title{
Os processos subjetivos de professores no trabalho pedagógico com alunos com altas habilidades/superdotação
}

\section{The subjective processes of teachers in the pedagogical work with students with high abilities/giftedness}

\author{
Patrícia Melo do Monte ${ }^{1}$ \\ Ana Valéria Marques Fortes Lustosa ${ }^{2}$
}

\section{RESUMO}

O paradigma da inclusão escolar apresenta novas exigências ao ofício de ser professor, demandando que as práticas pedagógicas sejam organizadas a fim de atender às expectativas e às necessidades de um grupo amplo de alunos, incluindo os alunos com altas habilidades/superdotação - AH/SD. Com o intuito de avançar nas discussões que tratam do trabalho pedagógico sob uma perspectiva descritiva, reducionista e instrumental, propõe-se a sua investigação a partir das relações e contradições, que caracterizam a subjetividade humana. O objetivo principal deste estudo foi ampliar as perspectivas de análise da prática pedagógica, redimensionando esse conceito ao discuti-lo a partir da subjetividade em uma dimensão complexa, e favorecer a compreensão dos processos subjetivos do professor e do espaço escolar bem como as suas expressões sobre o trabalho desenvolvido junto a alunos com AH/SD. A Teoria da Subjetividade, desenvolvida numa perspectiva cultural-histórica por González Rey, orienta este estudo, que também se apoia na Epistemologia Qualitativa e no método construtivo-interpretativo. $\mathrm{O}$ estudo foi realizado com uma professora que atua com alunos com AH/SD em uma escola regular, privada, em Teresina, a partir de
\end{abstract}

\begin{abstract}
The school inclusion paradigm presents new demands on the craft of being a teacher, requiring that pedagogical practices be intentionally organized to meet expectations and needs of a broad group of students, including the ones who move away from regular performance, such as those with high abilities/giftedness (HA/G). Aiming to advance in the discussions that deal with pedagogical work under a descriptive, reductionist and instrumental perspective, this study proposes the investigation of pedagogical practices based on relationships and contradictions, which characterize human subjectivity. The main objective of this study was to broaden the perspectives of analysis of pedagogical practice, resizing this concept by discussing it from the subjectivity in a complex dimension, and favoring the understanding of the subjective processes of the teacher and the school space as well as their implications on the subject the work developed with students with HA/G. The Theory of Subjectivity, developed from a cultural historical perspective by González Rey, guides this study, which is also based on Qualitative Epistemology and the constructivistinterpretive method. The study was carried out with a teacher who works with students with HA/G in a regular school in Teresina, such as interviews, sentence completion and
\end{abstract}

\footnotetext{
${ }^{1}$ Psicóloga, Doutora em Educação. Professora do Centro de Ciências da Saúde da Universidade Estadual do Piauí. Professora do Curso de Psicologia do Centro Universitário Santo Agostinho. Email: patriciamelo2000@gmail.com

2 Psicóloga, Doutora em Psicologia. Professora do Programa de Pós-Graduação em Educação da Universidade Federal do Piauí. E-mail: avfortes@gmail.com
} 
entrevistas, completamento de frases e composição. As informações resultantes do processo construtivo-interpretativo apontam que a produção coletiva e dialógica do trabalho pedagógico viabiliza ao grupo de professores a configuração de um espaço de formação mútua; há organicidade nas ações desenvolvidas pelos professores da sala comum e do Atendimento Educacional Especializado; há a circulação de elevadas expectativas de aprendizagem em relação aos alunos. Todos esses processos integram a rede de sentidos subjetivos que circulam na instituição, constituindo a sua subjetividade social como favorecedora de práticas pedagógicas inclusivas em relação ao aluno com AH/SD.

Palavras-chave: Teoria da Subjetividade. Trabalho pedagógico. Inclusão escolar. Altas habilidades/superdotação. Subjetividade social. composition. Resulting information from the constructivist-interpretive process points collective and dialogical production of pedagogical work, which enables the group of teachers to configure a space of mutual formation; organic unity in the actions developed by common classroom teachers and SES (Specialized Educational Service) teachers; circulation of high learning expectations in relation to students. All these processes integrate the network of subjective meanings that circule in the institution, constituting its social subjectivity as a favoring of inclusive pedagogical practices in relation to the student with $\mathrm{HA} / \mathrm{G}$.

Keywords: Theory of Subjectivity. Pedagogical work. School inclusion. High abilities/giftedness. Social Subjectivity.

\section{Introdução}

O paradigma da inclusão escolar desafia significativamente o professor em seu fazer, realçando importantes demandas no processo de qualificação desse profissional. Diante da urgência de um sistema educacional inclusivo, grande número de educadores demonstra inquietação e perplexidade, por perceberem suas referências para o desenvolvimento desse trabalho diluídas e pouco adaptadas às exigências contemporâneas.

Sob a perspectiva da inclusão escolar, na sala de aula não mais figuram alunos padronizados, mas um grupo diverso e desigual. Considerar as idiossincrasias dos alunos requer que os docentes reestruturem seus saberes, reposicionem-se e mudem sua prática para conhecê-las e atendê-las. Nesse contexto, os docentes buscam com ansiedade uma nova instrumentalização para lidar com esse aluno.

A escola inclusiva busca adaptar-se à multiplicidade do funcionamento humano e rompe com o paradigma positivista que legitima um padrão escolhido, prescreve padrões de ensino e de aprendizagem e engendra processos de exclusão social (GOMES; GONZÁLEZ REY, 2007). Embora se 
reconheçam significativos movimentos e avanços rumo à construção de escolas inclusivas, os dispositivos legais ainda não alcançam a complexidade da realidade do sistema educacional brasileiro.

Há muitas fragilidades na política de inclusão escolar como, por exemplo, a inexistência de indicativos seguros sobre a quantificação da população que demanda atendimento em Educação Especial (Pérez, Freitas, 2014); a simplificação dos serviços de apoio, oferecendo no que se refere ao atendimento nas Salas de Recursos Multifuncionais (SRM) "serviço tamanho único" (MENDES, CIA, TANNÚS-VALADÃO, 2015, p.34), sem considerar as especificidades dos alunos; os dissensos e as lacunas da formação de professores para atender aos alunos Público-Alvo da Educação Especial PAEE (MORI; BRANDÃO, 2009; MENDES; CIA; CABRAL, 2015); dentre outros aspectos.

Ao se considerar a área das AH/SD, de forma específica, as dificuldades se avolumam. Na implementação das políticas públicas educacionais, de forma recorrente, a ênfase recai sobre as deficiências, ratificando a invisibilidade dos alunos com AH/SD e os processos de exclusão que eles vivenciam (PÉREZ, 2003; PÉREZ; FREITAS, 2014).

Para Guenther (2003), a Educação deve incumbir-se de evitar que o talento humano seja perdido, ou desviado, e proporcionar a estimulação e orientação necessária ao desenvolvimento sadio e apropriado do sujeito. No entanto, quando analisamos práticas pedagógicas voltadas a atender às necessidades dos alunos com AH/SD, deparamo-nos com um grande número de atividades que visam ao desenvolvimento de habilidades cognitivas, reduzindo o aluno a esse domínio, e com poucos programas voltados para o desenvolvimento de habilidades socioemocionais (CHAGAS, 2008).

Dentre as práticas pedagógicas comumente discutidas que visam à inclusão escolar da pessoa com AH/SD, estão: o enriquecimento escolar, a aceleração da aprendizagem, o acompanhamento por monitores, a participação em eventos, gincanas e amostras, programas de férias, cursos de capacitação, dentre outros (CHAGAS; FERREIRA, 2014). Tais práticas focam em processos 
organizativos do ensino, destacando metodologias e instrumentos que facilitam um maior desempenho dos alunos. É importante destacar que os processos subjetivos que ocorrem nos alunos, como também nos professores, são, muitas vezes, negligenciados nessas práticas. Como reiteram Rossato, Matos, Paula (2018), a constituição da subjetividade do professor tem sido, com frequência, ignorada nos processos de formação inicial e continuada e no cotidiano escolar.

Práticas pedagógicas excessivamente tecnicistas e burocráticas despersonalizam o sujeito que as exerce e retiram de si a possibilidade de pautar-se por critérios que garantam sua legitimidade (FRANCO, 2017). Para a autora, escolas que admitem tais práticas tendem a se distanciarem do significado de formação de sujeitos como pessoas autônomas e críticas. Diante dessas inquietações, questionamos: Como a Teoria da Subjetividade pode contribuir na compreensão das práticas pedagógicas de professores de alunos com AH/SD?

Nesse estudo, buscamos, portanto, ampliar as perspectivas de análise da prática pedagógica, redimensionando esse conceito ao discuti-lo a partir da subjetividade em uma dimensão complexa, e favorecer a compreensão dos processos subjetivos do professor e do espaço escolar bem como as suas implicações sobre o trabalho desenvolvido junto a alunos com AH/SD.

\section{Metodologia}

Este estudo se pauta nos fundamentos da Epistemologia Qualitativa e no método construtivo-interpretativo.

González Rey, associando-se ao pensamento de outros autores contemporâneos, como Allport (1978), Morin (2011) e Bachelard (2006), desafia as convicções da ciência moderna. De modo subversivo, confrontam as certezas, a previsibilidade, a ordem da ciência. Entendem que a ciência não se alimenta de simplismos e constâncias. Fazer ciência implica produzir conhecimentos e essa produção ultrapassa a função de coletor de dados para, posteriormente, relacioná-los a uma teoria e escrever um relatório. Fazer ciência é atuar como 
sujeito ativo e reflexivo na construção do conhecimento, e nessa elaboração, a interação com os participantes é legítima e necessária.

A Epistemologia Qualitativa surge, pois, sobre esses alicerces. González Rey, como epistemólogo, cria condições dentro de uma perspectiva científica para o estudo da subjetividade, concebida como um sistema simbólicoemocional, complexo, produzido de forma simultânea nos níveis social e individual, que integra sistemas e espaços sociais diferentes situados em dimensões espaço-temporais distantes (GONZÁLEZ REY, 2003, 2007, 2011; GONZÁLEZ REY; MITJÁNS MARTÍNEZ, 2017; ROSSATO, 2011). Por conseguinte, estudar a subjetividade requer que adentremos nos modos profundamente complexos de constituição do sujeito e sigamos na produção de conhecimento por caminhos que não são lineares e tampouco explícitos (Pinto; Paula, 2018).

A teoria é considerada um processo vivo, que está em constante desenvolvimento, e sua construção exige que o pesquisador ocupe um lugar de sujeito de reflexão, portanto, autor. Seu trabalho deve pautar-se, portanto, em três princípios basilares: o reconhecimento da singularidade como nível legítimo da produção do conhecimento; o conhecimento sobre a subjetividade como uma produção construtivo-interpretativa; e a compreensão da pesquisa como processo de comunicação dialógica (GONZÁLEZ REY, 2005, 2011; GONZÁLEZ REY; MITJÁNS MARTÍNEZ, 2017).

$\mathrm{Na}$ Epistemologia Qualitativa, o singular alcançou status epistemológico, por representar "informação diferenciada que se fundamenta no caso específico que toma significado em um modelo teórico que o transcende" (GONZÁLEZ REY; MITJÁNS MARTÍNEZ, 2017, p. 29). Nesse modo particular de investigação, ressaltamos o valor da qualidade da informação, que é produzida a partir de expressões diversas do sujeito.

A instituição escolar onde foi desenvolvido o estudo é privada e localizase na região central de Teresina. Foi fundada há 74 anos, oferece como níveis de ensino a Educação Infantil (creche e pré-escola), o Ensino Fundamental e o Ensino Médio e tem como missão formar pessoas intelectual e eticamente 
autônomas, que sejam livres para refletir, questionar, criticar e transformar a realidade em que vivem, contribuindo para que ela se torne melhor.

A escola, há uma década, destaca-se entre as dez melhores escolas do país, a partir dos indicadores de desempenho do Instituto Nacional de Estudos e Pesquisas Educacionais Anísio Teixeira - INEP, vinculado ao Ministério da Educação - MEC. Em relação aos resultados do Exame Nacional do Ensino Médio - ENEM, em 2015, a escola obteve o $2^{\circ}$ lugar nacional pela média simples, $7^{\circ}$ lugar nacional nas provas objetivas do Brasil e $2^{\circ}$ lugar nacional na Redação (http://portal.inep.gov.br).

Sua estrutura física é ampla, confortável e bem higienizada. Possui aproximadamente 3000 alunos e 900 funcionários. O currículo da escola é extenso, com carga horária de sete horas diárias, e com amplitude de disciplinas, possibilitando aos alunos acesso a diversas áreas do conhecimento, em um plano teórico e experiencial. É um currículo construído com possibilidades de enriquecimento para todos os alunos, incluindo o aluno com AH/SD.

Esse estudo envolveu a principalmente a participação de uma professora de sala regular, do Ensino Fundamental - Anos Finais, que dentre os seus alunos há estudantes com diagnóstico de AH/SD, a quem chamamos de Lia, e outros 11 colaboradores (professores, coordenadoras e psicólogos). Para a seleção dos professores participantes, foram usados como critérios: além de serem professores de alunos com AH/SD, devidamente identificados, no período da realização da pesquisa, deveriam atuar como docentes na instituição há mais de 2 anos; pertencer a áreas diversas; ter interesse e disponibilidade para participar da pesquisa.

Durante a pesquisa, utilizamos instrumentos orais e escritos, mas privilegiamos os primeiros. A combinação dos instrumentos visou, sobretudo, a criação de diferentes possibilidades para que, por meio delas, os participantes pudessem refletir e se expressar. Foram utilizados os sistemas conversacionais, buscando a expressão espontânea e compromissada do sujeito que conversa (GONZÁLEZ REY, 2005). As conversas foram 
estimuladas por meio de perguntas geradoras, com o objetivo de envolver os participantes nos temas, despertando curiosidades, necessidades e interesses. As entrevistas foram realizadas de forma semiestruturada, com questões abertas, visando à criação de um espaço dialógico e reflexivo entre pesquisadora e participante, a partir de um roteiro organizado de acordo com os objetivos da pesquisa. A entrevista inicial foi estruturada a partir de quatro eixos: caracterização do professor entrevistado; concepções acerca das altas habilidades/superdotação e inclusão escolar; caracterização da prática docente; o trabalho pedagógico com o aluno com AH/SD.

No trânsito da pesquisa, fizemos observação de reuniões pedagógicas, o que foi significativo pois possibilitou a inserção junto ao grupo e a compreensão da complexidade da instituição (rotinas, do sistema avaliativo, de processos de formação continuada, de demandas mais comuns em relação aos alunos e às famílias, compreensão do papel da psicologia junto à equipe pedagógica, entre outras informações). Foram analisados documentos, como o Projeto Político Pedagógico da Escola, jornais eletrônicos, notícias divulgadas no site institucional, galeria de fotos, regulamentos de gincanas e projetos, depoimentos no site institucional e em sites locais, instrumentos valiosos na confrontação das informações e por permitir acesso ao discurso oficial da instituição em relação aos seus modos de funcionamento, que integra a subjetividade social da escola. A análise destes documentos também contribuiu para conhecermos aspectos históricos, estruturais e aspectos pedagógicos que fundamentam a ação docente na escola. Foram utilizados ainda o completamento de frases, com indutores curtos, preenchidos pela participante, com temas específicos relacionados aos objetivos da pesquisa, como: No trabalho... O aluno com AH/SD... Na escola, eu... Minha família... e indutores indiretos, como Eu... Gostaria... Lamento...; a Composição consistiu no desenvolvimento escrito de determinados temas. Nesta pesquisa, a participante compôs dois textos, que foram úteis para elaboração de indicadores sobre os seus modos de subjetivação em relação à escola e a outras dimensões de sua vida; e sobre o seu modo de perceber o aluno com AH/SD e 
subjetivar a sua relação com ele. Os temas foram: A escola em que trabalho $e$ Como vejo o(a) meu(minha) aluno(a) com AH/SD.

Para González Rey e Mitjáns Martínez (2017), todo o curso da pesquisa pode ser considerado processo de construção da informação, pois a informação que vai sendo relevante para o problema estudado não aparece diretamente da resposta dos participantes, nem de sua fala explícita, mas nas hipóteses que vão ganhando força, organizadas pelos indicadores que o pesquisador constrói fundamentado nas expressões dos participantes nos mais diversos momentos e contextos da pesquisa. Com a articulação dos indicadores, surgem as hipóteses, as quais não se constituem a priori, e tampouco devem ser levadas à experimentação; mas são consideradas vias nas quais o modelo teórico vai ganhando capacidade explicativa. O autor denominou essa forma de trabalhar a informação de lógica configuracional, por se apresentar em um jogo contínuo de indicadores em relação.

\section{$\mathrm{O}$ autor, os fundamentos e a intensidade de sua obra}

Pensar sobre a subjetividade hoje exige incluir as contribuições de Fernando Luís González Rey, que se dedicou de forma incansável à temática, em uma perspectiva cultural-histórica, nas últimas décadas. O autor, na elaboração de seu pensamento, apresentou um questionar-se constante, uma compreensão de diferentes perspectivas da Psicologia e uma capacidade de se comunicar com outros campos teóricos, que nos possibilitaram uma reflexão ampliada sobre o sujeito e suas relações. Inspirando-se, sobretudo, nas ideias de Vigotski, González Rey elaborou o arcabouço de sua teoria psicológica sobre a subjetividade, com o desafio de se contrapor aos modelos psicológicos dominantes.

O autor rompeu com o pensamento psicológico moderno, que abordava os fenômenos psicológicos sob um paradigma descritivo-instrumental e os concebia como tendências universais de organização do psíquico; e também concebia a subjetividade como centralizada na figura do indivíduo, ligada a um 
universo privado de emoções e sentimentos. González Rey ousou pensá-la como produção cultural-histórica, representando-a como um sistema complexo e em contínuo desenvolvimento. O seu sistema teórico, conhecido como Teoria da Subjetividade, passou a representar a expressão do paradigma da complexidade na Psicologia (MITJÁNS MARTÍNEZ, 2005).

Seus textos carregam a vivacidade e a intensidade de sua produção. A processualidade é uma marca de sua construção teórica e evidencia-se quando González Rey de forma frequente revisitou seus escritos e os perspectivou em relação às pesquisas orientadas por ele e por grande número de pesquisadores nos campos da psicologia social, da saúde, da clínica, do desenvolvimento humano e da educação.

$\mathrm{Na}$ trama conceitual tecida pelo autor, os conceitos são recursos de inteligibilidade que ganham significado no campo da pesquisa ou da prática profissional. Eles não existem como construtos universais, que conduzem uma pesquisa de forma a acomodar as informações que surgem na investigação. Afirma que os "conceitos, suas relações e desdobramentos não estão dados de uma vez por todas, mas são recursos do pensamento que vão mudando e ganhando novos significados dentro das próprias tramas teóricas que se desenvolvem com fundamento neles" (GONZÁLEZ REY; MITJÁNS MARTÍNEZ, 2017, p.32).

Os conceitos, para o autor, são continuamente desafiados pelo campo, considerado um sistema vivo de relações, e, assim, têm a possibilidade de alcançar níveis mais elevados de desenvolvimento. Exemplifica:

Como tem acontecido com todas as categorias que têm sido articuladas no corpo integral desta proposta teórica, o conceito do sujeito não abarcava, num primeiro momento, a complexidade das tramas subjetivas que o configuram e das quais o sujeito faz parte ativa; as especificidades que foram incorporadas depois no decorrer do desenvolvimento da teoria (GONZÁLEZ REY; MITJÁNS MARTÍNEZ, 2017, p.66).

Dessa forma, o autor revisou conceitos e expandiu categorias, evidenciando lucidez e coerência com os pressupostos de um pensamento 
científico dinâmico. Neste estudo, a proposta é investigar os processos subjetivos expressos nas práticas pedagógicas e, por isso, é necessário esclarecer o que consideramos subjetivo. Subjetivo refere-se a um tipo de processo que emerge como qualidade da cultura, sendo parte dela e produzido em diferentes espaços sociais, dentro dos quais culturas diferentes se desenvolvem de forma simultânea em um mesmo tempo histórico (GONZÁLEZ REY, 2015). O subjetivo, na concepção adotada, não deve ser reduzido a elementos ou entidades dadas e, ao mesmo tempo, não deve ser considerado sob uma visão holística como identificação integradora do todo. O subjetivo é um sistema que não corresponde à totalidade da subjetividade da pessoa nem de espaço social particular. Enquanto configuração atual de processos, o subjetivo se organiza no curso da ação e no curso da história de vida das pessoas e de seus espaços sociais, alimentando-se das múltiplas produções simbólico-emocionais resultantes de diferentes experiências dessas pessoas em tempos e contextos diferentes da vida individual e social (GONZÁLEZ REY, 2015).

Desse modo, entendemos a produção subjetiva como a expressão do que foi vivido, que integra experiências históricas e atuais do indivíduo, e organizase a partir de sua história de vida e de diferentes contextos sociais, sensível a múltiplos desdobramentos no curso da ação do indivíduo. E como compreender a subjetividade na perspectiva de González Rey? "Os conceitos desenvolvidos por nós para gerar a visibilidade dos processos e formas de organização da subjetividade são: sentidos subjetivos, configurações subjetivas, sujeito, subjetividade social e subjetividade individual" (GONZÁLEZ REY; MITJÁNS MARTÍNEZ, 2017, p. 62).

Compreendê-la exige ultrapassar as representações estático-descritivas da subjetividade enquanto elemento intrapsíquico e secundário na compreensão dos fenômenos psíquicos. O autor se contrapôs ao caráter universal da subjetividade e evidenciou o seu caráter configuracional, constituído em dimensões sociais e temporais diversas. 
Sua teoria permite compreender o homem como resultado de sua complexa realidade social sem, para isso, desmembrar a unidade do social e do individual. São considerados sistemas ontologicamente diferentes - o social e o individual -, embora capazes de integrar-se na subjetividade, ante a emergência da cultura como definidora do espaço social. Percebe-se, portanto, que diferentemente de outros sistemas psicológicos que antagonizam o social e o individual, a Teoria da Subjetividade os integra.

Os conceitos de sentido subjetivo e configuração subjetiva, presentes em seu sistema teórico, viabilizam a compreensão do social como subjetivamente configurado, o que permite transcender uma visão descritiva e compreendê-lo pelas configurações subjetivas geradas pelas pessoas e os espaços sociais em que elas vivem. Para o autor, "as consequências do social para a vida humana sempre estão atravessadas pelos processos de subjetivação das pessoas implicadas nas tramas sociais" (GONZÁLEZ REY, 2015, p. 19).

Alguns espaços sociais podem favorecer a produção de uma subjetividade social limitadora da expressão das pessoas, subordinando-as à dinâmica presente neste espaço. Por outro lado, existem aquelas pessoas ou grupos que se tornam capazes de sobrepujar espaços dominantes a partir de produções alternativas que definem uma tensão permanente entre sua produção e o socialmente estabelecido. É a partir deste movimento que emerge o sujeito.

A categoria sujeito constitui-se também de grande valor para as produções na Psicologia contemporânea. Do modo em que foi delineada pelo autor, sua relação com o social é essencialmente contraditória e recursiva. $\mathrm{O}$ sujeito particulariza-se dentro dos processos normativos de toda a sociedade e, desse modo, está associado ao caráter processual e à tensão que caracterizam a vida social, marcando um processo passível de mudanças permanentes e inesperadas, e não um sistema submetido a leis supraindividuais que decidem o destino da história (GONZÁLEZ REY, 2004).

O indivíduo ou grupo com capacidade de se posicionar, de gerar, com seus posicionamentos, processos que estão para além de seu controle e de sua consciência podem ser considerados sujeitos (GONZÁLEZ REY; MITJÁNS 
MARTÍNEZ, 2017). Ele não está preso às determinações históricas, mas age em função de suas configurações subjetivas e das características da subjetividade social, ou seja, ele responde à sua realidade subjetiva.

Podemos concluir que nem toda pessoa ou grupo se posiciona como sujeito nos espaços sociais a que pertence. Desse modo, González Rey ampliou seu sistema conceitual com a inserção do conceito de agente. Caracterizou-o como o indivíduo - ou grupo social - situado no devir dos acontecimentos no campo atual de suas experiências; uma pessoa ou grupo que toma decisões cotidianas, pensa, gosta ou não do que lhe acontece, o que de fato lhe dá uma participação nesse transcurso, embora não apresente movimentos de ruptura com o espaço social normativo. Conforme o autor, o conceito de agente está associado "à capacidade dos indivíduos de serem ativos durante uma experiência, ainda que não sejam capazes de abrir novos processos de subjetivação ao vivê-la" (GONZÁLEZ REY; MITJÁNS MARTÍNEZ, 2017, p.77).

O conceito de configurações subjetivas possibilita apreender em sua complexa integração a diversidade de processos da vida social das pessoas por meio dos sentidos subjetivos que essas geram nas suas diferentes atividades. As configurações subjetivas são um momento de auto-organização que emerge no fluxo caótico de sentidos subjetivos e que define o curso de uma experiência de vida, especificando estados subjetivos dominantes (GONZÁLEZ REY, 2015, 2017). São produções de um sujeito em ação, situado em múltiplas tramas sociais simultâneas (GONZÁLEZ REY, 2013).

Os processos psíquicos, na maioria das vezes, aparecem como um momento de configuração subjetiva da ação, a qual é responsável pelo estado emocional que dinamiza esse processo. Em outras palavras, as configurações subjetivas representam as motivações mais complexas e relevantes dos indivíduos.

A compreensão da configuração subjetiva em seu caráter motivacional a define como um conceito integrador essencial da subjetividade humana; a configuração subjetiva não é uma soma de sentidos subjetivos, ela representa um sistema gerador 
de sentidos subjetivos com elevada convergência entre si, que se ergue como motivação essencial das ações e funções psicológicas implicadas em uma experiência particular, o que faz dessas ações e funções processos subjetivos, cujo curso é inseparável da configuração subjetiva da que são parte (GONZÁLEZ REY; MITJÁNS MARTÍNEZ, 2017, p.12).

Inferimos, portanto, que mudanças na motivação são indicadoras de novos processos de subjetivação. Com as mudanças, o sujeito busca novas formas de relação e de ação compatíveis com a organização e desenvolvimento de sua subjetividade, o que evidencia o seu caráter cultural e histórico.

Os sentidos subjetivos emergem no curso da experiência e se constituem como processos simbólico-emocionais, nas quais "o simbólico se torna emocional desde sua própria gênese, assim como as emoções vem a ser simbólicas, em um processo que define uma nova qualidade dessa integração, que é precisamente a definição ontológica da subjetividade" (GONZÁLEZ REY; MITJÁNS MARTÍNEZ, 2017, p. 63).

Estas categorias se constituem subsídios nesta investigação, com o propósito de melhor compreender como o docente experiencia o seu trabalho com alunos com altas habilidades/superdotação. Nesse estudo, considerar tais processos é relevante pelo entendimento, tal qual González Rey (2007, p. 174), de que "negar a subjetividade é equivalente a desconsiderar a força da produção humana mais genuína, e nos submeter ao domínio do instrumental”.

\section{Altas habilidades/superdotação: Alguns apontamentos}

O conceito de superdotação, ao longo do tempo, tem evoluído atrelado aos avanços no conceito de inteligência (FREITAS; PÉREZ, 2012). Historicamente, os modelos teóricos da inteligência, à medida que avançam de um modelo unidimensional para modelos multidimensionais, impactam na compreensão de que se tem sobre os indivíduos com AH/SD. Na discussão conceitual, a dimensão cognitiva se sobrepõe a todas as outras dimensões do desenvolvimento humano. 
O Grupo Columbus, da Universidade de Columbus, em Ohio (EUA), entretanto, propõe que a superdotação apresenta componentes cognitivos e emocionais discrepantes em relação à média da população, ou seja, compreende que a pessoa superdotada pensa diferente dos demais e sente de forma nitidamente distinta. Ao contrário de outras perspectivas teóricas, os estudiosos desse grupo, dentre eles Silverman (2002; 2013), dão ênfase às características socioemocionais desses indivíduos.

Cotidianamente, ao se discutir sobre o tema, sobressaem-se os conceitos que destacam a facilidade de aprendizagem do sujeito, o rápido domínio de conceitos e procedimentos, a destacada capacidade criativa. São perspectivas que, geralmente, reduzem o indivíduo a uma perspectiva de aprendente, desconsiderando, muitas vezes, o contexto que o envolve, suas condições emocionais e os estímulos de que ele necessita em seus diferentes processos de desenvolvimento.

Além do construto inteligência, quando se trata das AH/SD, também se considera de forma significativa a criatividade. Não há consensos a respeito da constituição desses processos (KAUFMAN; PLUCKER; BAER, 2008). Estudos sobre a inteligência geralmente abordam a sua natureza, a caracterização das habilidades que a constituem, a avaliação destas habilidades, como também os aspectos socioculturais que a influenciam (GARDNER, 1995; 2000). Nesta pesquisa, adotamos um modelo teórico que aborda a inteligência em sua multidimensionalidade, a Teoria das Múltiplas Inteligências de Gardner. Esta teoria compreende a mente humana como multifacetada, existindo capacidades distintas que podem receber a denominação de inteligência: lógico-matemática, linguística, musical, físico-cinestésica, espacial, interpessoal, intrapessoal, naturalista e a existencialista (GARDNER, 2000).

Na compreensão da criatividade, filiamo-nos ao pensamento de Mitjáns Martínez (2007; 2012), que a considera como um processo plurideterminado, mediatizado por fatores históricos, econômicos, socioculturais, econômicos, ideológicos e subjetivos. A autora concebe criatividade como um processo complexo da subjetividade humana e ressalta: "na possibilidade de criar algo 
'novo' e 'valioso' está implicada, entre outros fatores, uma configuração de processos subjetivos, tanto da subjetividade individual como da subjetividade social, que, a meu ver, constitui a essência da criatividade" (MITJÁNS MARTÍNEZ, 2007, p. 54).

Consideramos muito relevante na perspectiva teórica adotada o fato de que rompe com a ideia de que a criatividade é inata e com a ideia de que é uma característica global do sujeito, ou seja, não se expressa de forma generalizada em todas as suas atividades. A criatividade se expressa em formas e contextos diversos, em diferentes níveis e graus, e a "expressão criativa resulta da implicação afetiva do sujeito em uma determinada atividade para a qual ele está motivado" (AMARAL; MITJÁNS MARTÍNEZ, 2009, p.162).

A noção de AH/SD não se resume a um escore de inteligência, passível de ser medido, como se acreditou durante muito tempo; exige considerar um conjunto de características cognitivas, comportamentais e socioemocionais, e sua inter-relação com o contexto no qual a pessoa está inserida, o que impossibilita se falar sobre um perfil único.

Uma abordagem teórica que empreende esforços na conceitualização das AH/SD é a desenvolvida por Renzulli (2004, 2013), conhecida como Concepção dos Três Anéis. Esse é um dos referenciais adotados no Brasil na elaboração de propostas pedagógicas e políticas públicas e nos alinhamos a ele por reconhecermos alguns pontos de conexão com os aportes teóricos assumidos.

Renzulli (2011) explica a superdotação como resultado da interação de três fatores: habilidade acima da média, envolvimento com a tarefa (motivação) e criatividade. Nenhum dos fatores é mais importante que o outro e não precisam necessariamente estar presentes ao mesmo tempo e na mesma proporção para que os comportamentos de superdotação se concretizem.

O modelo de Renzulli (2011) trouxe contribuições expressivas para a área, ao considerar o indivíduo com altas habilidades/superdotação de forma integral, considerando a intervenção de fatores genéticos e ambientais na sua constituição, e de forma multifacetada. Além dos anéis representando as áreas, 
o autor enfatizou o fundo das figuras, representando a personalidade e o ambiente contribuindo para a manifestação dos três anéis. Renzulli (2013), revisitando os conceitos que desenvolveu há quase três décadas, reconhece a limitação de seu construto teórico por não ter contemplado com clareza e profundidade os processos subjetivos e contextuais. Afirma que uma "investigação desse tipo podia ter levado a um outro anel, que poderia refletir o grupamento dos traços afetivos, não diferentes das inteligências inter e intrapessoal de Gardner (1983) ou da inteligência emocional de Goleman (1995)" (RENZULLI, 2013, p.23).

Renzulli (2013) prefere falar em comportamentos de superdotação em vez de adjetivar o indivíduo como sendo ou não superdotado. Acredita que a superdotação "emerge ou se esvai em diferentes épocas e sob diferentes circunstâncias da vida de uma pessoa" (RENZULLI, 2004, p. 80). Propõe duas amplas categorias de habilidades superiores nas quais o indivíduo pode ser identificado: a superdotação escolar ou acadêmica e a superdotação criativoprodutiva. A superdotação acadêmica é o tipo mais facilmente identificado pelos testes padronizados de capacidade. As competências que os jovens apresentam nos testes de capacidade cognitiva coincidem com os tipos de capacidades mais valorizados nas situações de aprendizagem escolar tradicional, que focalizam as habilidades analíticas em lugar das habilidades criativas ou práticas. A superdotação produtivo-criativa descreve aspectos da atividade e do envolvimento humanos nos quais se incentiva o desenvolvimento de ideias, produtos, expressões artísticas originais e áreas do conhecimento. Destacamos que alunos com características produtivo-criativas podem não se adaptar a escolas cuja subjetividade social é marcada por movimentos de limitar a expressão das pessoas, contendo a fluência de ideias e o pensamento divergente.

A escola assume, então, papel fundamental de proporcionar oportunidades educativas que contemplem o desafio, o envolvimento e o encorajamento. Sabemos, entretanto, que no seu sistema a escola não consegue muitas vezes dar resposta a grupos minoritários e por isso as suas práticas 
acabam muitas vezes por não proporcionar atividades que desafiem as suas necessidades (BAHIA; TRINDADE, 2013); e a falta de desafio no contexto escolar pode conduzir à falta de investimento de alguns alunos superdotados ou mesmo ao risco de abandono ou de outros sinais de inadaptação (MORRIS, 2013).

Ressaltamos que, no Brasil, a superdotação ainda é vista como um fenômeno raro e, diante do indivíduo com essas características, a reação comumente apresentada é de espanto e de curiosidade. São muitas as concepções equivocadas a seu respeito, enraizadas no pensamento popular. Informação insuficiente, preconceito e tradição fundamentam uma série de ideias que interferem e dificultam a implementação de programas direcionados a esses sujeitos no sistema público e particular de ensino (Monte, 2009). Acreditamos que tais crenças, ao perpassarem a subjetividade social da escola, impactam significativamente as relações sociais e o trabalho pedagógico.

\section{O trabalho pedagógico do professor junto ao aluno com AH/SD, na escola regular, com ênfase nos processos subjetivos produzidos nessa relação}

A ausência de ambientes criativos, a falta de estímulos, de recursos, de oportunidades e o não atendimento das necessidades das pessoas com altas habilidades/superdotação, constituem, frequentemente, as causas do não desenvolvimento das capacidades latentes ou da involução de capacidades reveladas, levando ao isolamento em relação aos pares e criando fatores de risco para patologias futuras (CROSS; COLEMAN, 2014). Assim, torna-se essencial um contexto marcado por relações humanas e valores que possibilitem a conservação e a valorização do eu; marcado não pela ameaça de ser considerado um estranho ou por situações que impeçam no sujeito a construção de crenças de autorreferência positivas; um ambiente que favoreça à pessoa sentir-se amada, aceita e respeitada (PALUDO; LOOS-SANT'ANA; SANT'ANA-LOOS, 2014). 
Com o intuito de responder aos desafios que lhe surgem, faz-se necessário que o professor reconsidere o seu papel profissional, o seu compromisso político e sua competência técnica. A atitude reflexiva pressupõe atitude de pesquisa dos professores, cuja importância reside na possibilidade de se romper, através dela, com modelos pedagógicos que já não atendem às exigências contemporâneas, visto que os obriga a pensar e a rever posicionamentos. Considerando tais ideias, o professor desempenha importante papel de agente de transformação e precisa, portanto, estar consciente da ação que realiza e dos resultados decorrentes dela. Enfatizamos, assim, que essa condição de reflexividade requer que o profissional esteja em constante processo de formação, com a finalidade de adquirir os subsídios necessários para orientar sua prática.

Os professores da instituição analisada possuem formação acadêmica, com pós-graduação a nível de especialização, mestrado e doutorado. Em seu horário pedagógico, há momento disponível para contato com os pais/responsáveis e com o aluno em um âmbito individualizado e, além disso, a são realizadas reuniões com periodicidade semanal entre os profissionais. As reuniões ocorrem regularmente com diferentes finalidades: uma reunião com todos os professores da disciplina e outra reunião com os professores da área de determinado nível de ensino, ambas conduzidas pelo coordenador da disciplina, com a finalidade de estudo, aprofundamento e discussão de metodologias e recursos específicos da área; a terceira reunião é organizada pelo coordenador pedagógico e psicólogos, incluindo todos os professores de séries específicas. As reuniões consistem em espaços favoráveis à formação profissional, com aquisição de conhecimentos, escuta, compartilhamento dos problemas, planejamento, busca de soluções e fortalecimento, como podemos verificar nos trechos abaixo.

O trabalho da coordenação de disciplina eu acho muito bom no sentido de ampliar nosso ponto de vista, com o estudo dos textos, e também no sentido de dar retorno para as nossas dificuldades. Ele ouve, espera que o professor diga como vai proceder, mas ele não espera só o professor, ele elabora também. Se o professor, por exemplo, não souber como proceder naquele momento, ele dá assistência, sugere "vamos 
tentar dessa forma?" e acompanha, tem essa preocupação. [...]nós temos um grupo de professores, que a gente senta, a gente passa as práticas de um para o outro semanalmente, não tem como sentir que faz um trabalho solitário aqui dentro. Há partilha, desejo de melhorar compartilhado._(entrevista com a Professora Lia).

O modelo adotado pela escola afasta-se de um modelo comum de docência como jornada solitária (ARROYO, 2000) e intuitiva. O trabalho coletivo desenvolvido pelos profissionais se fundamenta, assim, nas necessidades surgidas no contexto escolar e se caracteriza pelo debate, pela troca de saberes, por experimentações, pela processualidade e continuidade das ações. Nas entrevistas realizadas, encontramos indicadores de que o funcionamento grupal mobiliza emoções e processos simbólicos dos professores, facilitando o seu envolvimento nesse contexto. Em nossa interpretação, as reuniões sistemáticas que ocorrem entre os profissionais da escola assumem importante função, por fomentarem uma cultura de abordagem dos problemas emergentes no trabalho pedagógico em uma perspectiva coletiva, havendo espaços de continência para as incertezas, as inquietações, as falhas e sucessos que ocorrem nesse processo, possibilitando aos docentes sentimentos de apoio e segurança na realização de seu trabalho.

Kinoshita (2009) pontua que, ao compartilhar a experiência pedagógica, cada profissional apresenta sua bagagem de formação e, na constituição de um espaço real de compartilhamento, surge uma relação de ajuda em busca de um fim comum, o movimento que antes era solitário passa a ser um movimento solidário. Desse modo, percebemos que a cultura da escola se expressa de uma forma ímpar, e isso a diferencia de grande parte das escolas brasileiras, nas quais os professores mal têm tempo de se ver e de planejar suas próprias aulas, de modo que os erros ocorrem e são silenciados, e muitas vezes nem percebidos de imediato, somente vistos pelos reflexos depois.

No grupo, há o encontro de diversas vivências, percepções, saberes e não saberes, e o diálogo é um meio que possibilita as conexões entre eles. Goulart (2017, p.239) afirma que o diálogo "representa um espaço social compartilhado, mediante o estabelecimento de um vínculo que ao mesmo tempo que mobiliza os atores envolvidos, não anula suas singularidades". Entendemos que a 
produção coletiva e dialógica do trabalho pedagógico viabiliza ao grupo a vivência de compartilhamento de saberes teóricos e técnicos e configura-se como espaço de formação mútua, estando cada professor, ao mesmo tempo, como formador e aprendiz. Ao vivenciar esses papeis, o professor tende a se sentir valorizado, a valorizar o trabalho que realiza e as relações que se dão no contexto escolar. Esses sentidos subjetivos despertam sentimentos de segurança e de pertencimento à instituição, como afirma Mundim (2016, p. 117):

A valorização do ambiente e das tramas que são tecidas, acarreta desejo de estar inserido em campos de ações pedagógicas, tais como os momentos de formação continuada, a criação de projetos, a troca de experiência e planejamento coletivo, de modo que o fato de pertencer a dinâmica e ao movimento construtor, faz com que busquem respostas próprias, singularizadas para as questões oriundas da vida escolar.

A autora explica que, na instituição escolar, o interesse pela qualidade do que é produzido contribui de forma significativa para a permanência dos profissionais naquele local, por conta do envolvimento com o processo de produção da dinâmica escolar. Santos (2013) contribui para esse entendimento ao afirmar que o sentimento de pertença é plurideterminado, constituído a partir da integração de sentidos subjetivos diversos, originados em processos subjetivos individuais e sociais, e está relacionado à ação da comunidade escolar.

\begin{abstract}
Eu me sinto muito bem aqui e a gente percebe que é um sentimento compartilhado. De modo geral, a relação dos profissionais com a escola é como se fosse mesmo de família, é muito interessante, eu acho que é isso que faz a diferença também na escola, não só isso, isso faz parte do conjunto de outras coisas. Eu já trabalhei em outras escolas e não existe isso não. [...] Eu costumo falar que todo professor, mesmo sendo um professor que vai para a universidade, ele poderia passar pelo (nome da escola ), porque aqui essa questão por exemplo do horário, a questão dos encontros, das reuniões, aqui é um espaço em que você não é somente professor, você também aprende a ser professor [...] (entrevista com a Professora Lia)
\end{abstract}

Dentre os desafios postos à formação de professores e às práticas pedagógicas na instituição está a inclusão das pessoas público-alvo da Educação Especial (PAEE). A fim de consolidar e apoiar o processo de inclusão 
que ocorria de forma pontual na instituição, foi instalado o Serviço de Inclusão, em maio de 2013 (SANTOS; CARVALHO, 2017). A equipe atualmente é composta por uma psicóloga, responsável pela Educação Infantil; uma pedagoga, responsável pelo Ensino Fundamental; aproximadamente vinte auxiliares de inclusão, e é coordenada por uma psicóloga, especialista em Educação Inclusiva e Gestão de Processos Educacionais. O serviço atualmente dispõe de duas Salas de Recursos Multifuncionais e é oferecido aos alunos que apresentam transtornos severos e aos alunos com dificuldades de aprendizagem, que, por meio de recursos variados de alta e baixa tecnologia, são estimulados em seus processos de aprendizagem.

O Atendimento Educacional Especializado (AEE) atualmente é desenvolvido numa perspectiva pedagógica, superando um modelo clínico que já existiu na instituição, e ocorre de forma articulada integrando diversos profissionais. Há evidências de organicidade e corresponsabilização nas ações desenvolvidas pelos professores da sala comum e do AEE na elaboração de alternativas didáticas direcionadas aos alunos PAEE, como podemos constatar nas falas:

\footnotetext{
Entrevistadora: Como é o seu contato, a sua relação com os professores da sala comum?

Professora de AEE: Nossa relação é direta! Nós sentamos uma vez por semana para fazer o planejamento geral, mas todos os dias eu converso com os professores de todas as áreas para pensar o material das crianças de todas as séries que a gente acompanha no Fundamental. Então, a gente traça o objetivo da semana, ou daquelas aulas que têm material pedagógico. A gente faz muito as tarefas adaptadas, as adaptações das atividades, então a gente pensa a atividade e posteriormente pensa o material complementar.
}

As práticas inclusivas desenvolvidas na escola compõem um ambiente de integração e de decisões compartilhadas, configurando o trabalho colaborativo entre professores especialistas e generalistas, psicólogos e coordenação pedagógica. O ensino colaborativo implica a redefinição do papel dos professores de ensino especial, como apoio centrado na classe comum e não somente serviços que envolvam a retirada dos alunos com deficiência das salas de aula regulares (VILARONGA; MENDES, 2014). Foram destacadas ainda 
como importantes o acompanhamento dos profissionais clínicos, da família e dos auxiliares no processo de inclusão escolar.

$\mathrm{Na}$ escola, algumas práticas pedagógicas já vêm se consolidando em relação à inclusão do aluno com deficiência; mas as intervenções dirigidas aos alunos com AH/SD não alcançam a coletividade dos professores. Segundo a coordenadora do Serviço de Inclusão, com esses alunos foram feitas intervenções pontuais a nível de AEE: a aceleração de um aluno da Educação Infantil, por solicitação da família, e a adaptação de recursos tecnológicos para o momento de avaliação no caso de outro aluno com dificuldades relacionadas à escrita. Atualmente há três alunos na instituição com diagnóstico de AH/SD, segundo os registros do Serviço de Inclusão, mas apenas um deles é acompanhado pelo setor, por apresentar dificuldades de aprendizagem. O AEE oferecido pela instituição revela-se, assim, com caráter complementar, inclusive no atendimento aos alunos com AH/SD, não atendendo à função suplementar, como recomenda a legislação específica. Compreendemos que essa organização se dá por conta do currículo enriquecido que a escola oferece a todos os alunos; não atribuindo, portanto, essa função exclusivamente ao AEE.

Observamos, de forma geral, que os professores não reconheciam de forma precisa entre os seus alunos aqueles que possuíam o diagnóstico de AH/SD e apresentavam muitas incertezas na sua caracterização. Identificamos que a visão dos professores sobre as AH/SD limitava-se a aspectos cognitivos dos alunos, destacando o domínio da inteligência, e de forma secundária o domínio da criatividade. Caracterizaram os alunos com alto rendimento como muito inteligentes ou muito compromissados/disciplinados. Questionamos: O que há por trás desses conceitos? O que justifica essa dúvida? Quais as implicações dela? Por que não os consideram alunos com AH/SD?

As incertezas dos professores em relação à classificação destes alunos podem ser explicadas por desconhecimento do campo teórico das AH/SD, destacando-se as crenças associadas à genialidade e à raridade desses alunos. Outra hipótese que podemos levantar é que há recusa em reconhecê-los como tal, por considerarem de forma consciente ou não, que no desenvolvimento da 
superdotação os aspectos biológicos seriam determinantes, em detrimento dos ambientais, não havendo, portanto, mérito da escola ou dos educadores no sucesso do aluno. Na representação da professora, ser superdotado envolve as ideias de indivíduo "preparado", que possui "domínio sobre os outros", é "bom aluno" e é raro.

O aluno superdotado... é muito bom ser professora de aluno superdotado, porque na verdade ele de alguma forma já está preparado. Mas não é a realidade das salas de aula, porque na verdade um aluno que traz de alguma forma esse conhecimento que não é comum, de modo geral, é uma exceção (Completamento de Frases - Professora Lia)

A professora compreendia altas habilidades restringindo-se ao tipo escolar/acadêmico, percebendo-os como indivíduos que apresentam bom desempenho escolar e não identificava necessidades educacionais especiais nesses alunos.

O (ALUNO B) não é um aluno 8, aluno 9... ele é 10 em todas disciplinas e tem outras habilidades extras, não é só é a questão das próprias disciplinas em sala de aula. Ele toca, canta, joga futebol, é bom em tudo que ele faz, ele pega os instrumentos e sai música fácil. É completo (Entrevista com a professora Lia).

Diante dessas expectativas, perguntamo-nos: esse suposto aluno tem direito a não entender algo, a ter dificuldades de se relacionar, a errar ou contestar, a apresentar-se com suas potencialidades e necessidades na sala de aula? Ao ser considerado como aquele aluno que surpreende a todos, significa também que ele subverte as certezas dos professores. E ao subvertê-las, desorganiza-os? Traz-lhes inquietações? Desafia-lhes em sua posição de detentores do conhecimento? Escapam ao controle e domínio dos professores?

Embora não se coloque nesse lugar, a professora Lia parece confirmar essas hipóteses quando responde na entrevista sobre a dificuldade que o professor iniciante pode ter com esse tipo de aluno.

Então, ele fica todo tempo buscando exemplos. O professor que não está preparado... lidar com o aluno como o (nome do aluno G) é uma situação difícil. [...] Eu acho que é difícil no sentido de que o aluno nos cede respostas além do nível esperado e ele também espera que o professor esteja numa situação que esteja preparado para poder dar uma condução pra ele. Então o que acontece? $O$ (nome do aluno G) zomba de professores que não dão a resposta condizente com o que ele espera. Muitas vezes, ele sabe até a resposta, mas ele lança justamente para saber até onde o professor vai. [...] A questão é mesmo essa de 
ficar desafiando, então fica até rindo. Meu Deus do céu, coitado do professor que entra em sala de aula (risos), que está em processo inicial, e se depara com um aluno desses. Ele sofre! Eu até comentei com a coordenação que as perguntas que ele faz são perguntas de nível universitário (entrevista com a professora Lia).

Neste excerto, a professora considera que o aluno com AH/SD requer do professor uma preparação diferenciada, uma vez que terá que enfrentar os desafios postos pelo tipo de raciocínio avançado do aluno, pela contextualização dos problemas, integração com outras áreas e pela confrontação de ideias.

Apresentaremos algumas informações sobre a trajetória de vida, acadêmica e profissional de nossa principal interlocutora. Aos 34 anos de idade, a professora Lia é casada e possui uma filha de 4 anos de idade, concebida após duas perdas gestacionais, aos dois meses e aos oito meses de gestação. Lia graduou-se em Letras Português, em uma instituição pública. Afirma que o que a conduziu à docência está relacionado ao seu interesse e habilidade para envolver-se com as pessoas e conversar, assim como funda-se no fato de ter sido aluna de um professor que lhe serviu de modelo de profissional.

Decidir pela docência exigiu-lhe enfrentamento em relação aos familiares, sendo a primeira da família a escolher essa profissão. As licenciaturas não eram valorizadas por sua família. Ainda no primeiro período do curso, percebeu-se satisfeita em relação à sua escolha; a partir do segundo período do curso, participou de monitorias e pesquisa. Lia deu continuidade ao curso dedicando-se ao estágio em uma escola pública e à pesquisa. Consideramos importante destacar que, mesmo no início do curso, sem aparato teórico significativo e experiência como docente, Lia começou a ensinar. Ressaltamos sua abertura a essa experiência e o seu desejo de aprender. Percebemos que, em meio a tantas experiências significativas que um curso de formação acadêmica proporciona, o ensino, através das monitorias e estágios, e a pesquisa se destacam expressivamente em suas memórias, atribuindo a eles delineamentos importantes em sua qualificação profissional. 
Enquanto estudante, Lia buscou a formação além do espaço acadêmico, o que está relacionado à sua capacidade de refletir sobre a sua formação inicial e perceber as suas limitações. Embora não percebesse estímulo para o exercício da docência, Lia preservou seu interesse.

A sala de aula... é o meu lugar. Em sala de aula eu me sinto feliz,é um momento que eu ponho em prática os meus conhecimentos.

Com frequência sinto... vontade de ajudar o próximo, vontade de ouvir músicas, vontade de estar me apropriando de coisas novas. Quando eu vou na livraria, por exemplo, eu fico buscando livros que me trazem sugestões para a sala de aula. Como é que pode?

Esse conjunto de indutores nos revelam que Lia produz sentidos subjetivos de prazer e satisfação em sala de aula e esses sentidos se integram a outros, como a necessidade de ajudar o próximo e a ânsia por aprender. A ação de ensinar parece integrar esses sentidos, uma vez que através do ensino ela pode ajudar os alunos e que, para ensinar bem, ela precisa se apropriar de mais conhecimentos. Ensinar e aprender estão profundamente imbrincados em Lia. Esses sentidos que já sobressaiam durante a graduação, entrelaçam-se à subjetividade social da escola, como evidenciamos nas práticas semanais de formação coletiva.

Lia trabalha com adolescentes e busca realizar uma prática pedagógica visando os objetivos educacionais, a partir de uma atitude dialógica e de envolvimento afetivo. É importante frisar que, com essa postura, a professora favorece a aprendizagem e o desenvolvimento subjetivo dos alunos, como explicam González Rey, Goulart e Bezerra (2016, p. 60): "o afeto gerado na comunicação é essencial em qualquer atividade orientada ao desenvolvimento subjetivo da criança. Sem um espaço de socialização em que a criança se sinta acolhida e segura, o desempenho dela em qualquer atividade estará comprometido".

Pesquisadora: Lia, como você qualifica o seu trabalho?

Professora Lia: [...] A minha preocupação com os meninos não é jogar conteúdo e sim, de fato, saber se eles estão aprendendo. A minha preocupação são as etapas, os processos, então o importante é que eles saíam da série com aquelas habilidades, com aquelas competências, digamos, bem marcadas. Eu amo os meninos (risos), é muito bom, sabe? Quando eu preciso chamar a atenção, eu sou muito da sistemática de dar chances. Por que eu faço isso? Porque eu sei que 
quando eu digo pra eles "eu estou dando a primeira chance, eu estou dando a segunda, na terceira não tem mais vez", eles entendem. Então eu mantenho e nesse momento quando eu tomo a decisão, eles saem tristes, porque na verdade, eles quebraram a regra que foi estabelecida entre nós, com o acordo. Não foi uma coisa que eu cheguei de forma autoritária e disse: "vai ser assim, saía e acabou". Em determinados momentos em que a situação exige, a gente tem que usar o argumento da autoridade, isso é fato, mas assim, de modo geral os combinados funcionam.

O trabalho aparece para Lia como uma importante configuração de sentidos. Dedica-se a ele não somente quando está em sala de aula ou na instituição, mas ele se prolonga em atividades relacionadas ao estudo, ao planejamento e à avaliação, e se estende ainda a seus momentos de lazer.

Eu gosto, os alunos gostam. O material que a gente utiliza em português é todo autoral, a gente não copia e tem essas situações que eu faço, de tirar foto, de montar material com situações do dia a dia. Então eu acho que quando a gente fala isso para o aluno, olha eu estava num momento de férias, eu fiz isso... tipo "Tia, você lembrou de nós!" (entrevista com a professora Lia).

Dedico a maior parte do meu tempo... Ao meu trabalho e à minha filha.

Diariamente me esforço... (suspiro), para ser uma boa mãe e, além disso, para fazer o meu trabalho corretamente. (Completamento de Frases)

Consideramos que o interesse de Lia em aprender, seu entusiasmo em ensinar e as relações afetivas que mantém com seus alunos favorecem a dedicação ao trabalho e a sua subjetivação como algo prazeroso, de forma dominante. O trabalho para ela não está circunscrito a um espaço ou a um tempo específico, é central em suas expressões afetivas.

A professora demonstra objeção a um trabalho reprodutivo e descontextualizado, com reiteradas críticas ao uso normativo da gramática e introduz inovações em seu trabalho, rompendo com elementos didáticopedagógicos tradicionais em relação ao ensino da língua, o que nos parece convergir com a subjetividade social da escola no sentido de estimular o protagonismo dos docentes e o processo autoral. 
A escola, ao proporcionar espaço para que a professora se perceba como pensante e confronte-se, ao validar as suas ideias e reconhecer o valor de suas produções, reafirma à Lia sua expressão como sujeito.

Nosso material é todo autoral, português é todo autoral. Estamos até pensando em publicação também (risos). Por exemplo, eu tirei a gramática do $7^{\circ}$ ano, e por que que eu tirei a gramática? Porque eu acho que ela não agrega tanto, ela, na verdade, subestima o aluno. De modo geral sim, há algumas gramáticas que são muito boas, mas elas só servem para o ensino médio. Então o que acontece? Com a retirada agora da gramática, os outros professores ficaram "ah! vocês vão receber reclamação, porque eu já fiz isso uma vez e não deu certo". Enfim, com a gente está dando certo, e no próximo ano, nós vamos pegar esses materiais que produzimos, vamos elaborar e organizar como se fossem espécies de capítulos, e assim fazer o livro para o aluno.

(entrevista com a professora Lia).

Barreto (2009) pontua que a ação pedagógica não se restringe à aquisição de técnicas, domínio de determinados conhecimentos e metodologias, numa dimensão estática, mas envolve um processo de construção e reconstrução, favorecendo reflexões mais ampliadas acerca dos afazeres no dia a dia e novas ações sobre a práxis docente. Nesse mesmo sentido, Mitjáns Martínez (2003) afirma que a ação criativa do professor em sala de aula demanda não só sua capacidade de elaborar atividades inovadoras que permitam atingir os objetivos educacionais de forma mais eficiente, mas também requer habilidades comunicativas que lhe permitam criar um espaço onde as atividades possam fazer sentido para o desenvolvimento da criatividade.

Em relação aos alunos com $\mathrm{AH} / \mathrm{SD}$, Lia identifica, na aquisição do conhecimento, que há um posicionamento diferenciado destes alunos em relação aos demais. Percebe que geralmente os alunos com AH/SD refletem sobre as informações apresentadas, resgatam conhecimentos adquiridos anteriormente, fazem relações com outros campos do saber, questionam, apresentam raciocínio lógico e criativo. Houve situações em que sentiu a necessidade de limitar a participação deles para que os demais alunos pudessem participar ou porque os outros alunos se queixavam por conta de interferências excessivas. Para Pérez (2004), a ânsia de conhecimentos desses alunos e o elevado grau de curiosidade fazem com que busquem informações 
bem mais que os colegas e os próprios professores. Na discussão de temas de seu interesse, costumam apresentar informações enriquecidas com dados obtidos em fontes diversas ou, questionam de forma excessiva, o que pode causar incômodo e interromper o curso da aula.

$\grave{A}$ s vezes, eles querem mostrar esses conhecimentos a mais que eles têm, seja em História ou outra área. No caso do (nome do aluno G), quando eu chegava para discutir uma obra literária, e eu não faço a discussão do livro pelo livro, eu tenho que trazer o contexto histórico, geográfico, se tiver. "Meu Deus, para que que eu fui falar de Revolução Francesa?" porque ele ficou trazendo tudo de História para poder me testar em sala de aula, e o interessante era que eu respondia. Ele "Tia, a senhora tem informações da História toda? Porque tudo a senhora sabe responder" (risos). (entrevista com Lia).

A professora revela disposição e interesse em debater com o aluno temas de áreas diversas. Conecta-se ao pensamento do aluno e demonstra desenvolver uma relação positiva com o conhecimento e a dúvida dele. Ao responder aos seus sucessivos desafios, Lia individualiza momentaneamente o ensino, cria condições para expandir ainda o raciocínio do aluno e, ao mesmo tempo, conduz os demais alunos a outros estágios, que provavelmente, não seriam alcançados espontaneamente na aula prevista. A relação da professora com a dúvida do aluno com AH/SD, dando-lhe atenção e atribuindo-lhe valor perante os demais, devolve a ele uma imagem de competência, ao mesmo tempo que Lia gera sentidos subjetivos de sua própria competência e valor.

Então, eu costumo dizer que a gente aprende a ser professor também com este tipo de aluno, porque são eles que vão te possibilitando diferentes situações e fazendo com que você aprenda a lidar com elas. Quando se sente inseguro, o movimento é de buscar o que falta.

Pesquisadora: Você considera que o aluno superdotado escapa ao controle e dominio do professor?

Lia: Mas isso é importante, porque, na verdade, quando a gente se programa para a sala de aula, isso não quer dizer que eu estou fechando, delimitando o funcionamento da minha aula. Está programada para ser assim, mas sempre vai ter algum aluno que poderá trazer evidências, questionamentos, opiniões que vão contribuir, e é isso que eu espero mesmo. Essa evidência que ele trouxe, eu já levo para outra sala, porque pode ser uma contribuição. Então ele favorece, não é que ele vai atrapalhar o meu trabalho, eu acho que ele vai contribuir com esse plano profissional, no sentido de agregar, trazer novos conhecimentos para os alunos e para mim. (entrevista com a professora) 
Percebemos, neste trecho, que ela não subjetiva a postura do aluno como ataque, ameaça, humilhação; pelo contrário, a professora produz sentidos de reconhecimento à importância dessas situações de testagem do professor, feita pelo aluno com AH/SD, destacando o seu potencial para o desenvolvimento de processos de aprendizagem para ambos. Lia considera que essa postura do aluno requer do professor uma preparação diferenciada, uma vez que terá que enfrentar os desafios postos pelo tipo de raciocínio avançado do aluno, pela contextualização dos problemas, integração com outras áreas e pela confrontação de ideias. Em nossa acepção, este é mais um indicador do posicionamento de Lia enquanto sujeito em seu trabalho pedagógico. Acreditamos que as produções subjetivas relacionadas à sua necessidade de ajudar, à ânsia por aprender e à sua competência profissional integram essa configuração, e dessa forma consegue proporcionar um espaço de inclusão e acolhimento ao aluno e de aprendizagem para ambos.

A professora relatou que frequentemente os alunos são convidados para irem ao quadro a fim de explicarem a sua compreensão sobre determinado problema. Entende que isso aproxima os alunos, favorece o desenvolvimento de habilidades de partilha, exposição do pensamento e facilita a aprendizagem dos outros, por semelhança no padrão de linguagem utilizada. A professora percebe os alunos com AH/SD como facilitadores do trabalho pedagógico, uma vez que eles facilitam a aprendizagem dos colegas e, muitas vezes, direcionam o pensamento dela para pontos relevantes e de interesse para a faixa etária deles.

Para Mitjáns Martínez e Amaral (2009), nas situações de ensino em que a conformidade é mais valorizada que a originalidade, espera-se que os processos educativos não promovam no aluno a implicação e o interesse necessários para as atividades desenvolvidas. Consequentemente, o aluno poderá manter-se indiferente à ação educativa respondendo a ela de maneira formal. No caso de alunos com AH/SD, essa situação fica muito evidente. É o que ocorre, muitas vezes, quando o estudante é limitado pelo professor em sua capacidade imaginativa e é orientado a percorrer os caminhos que os demais 
seguiram na elaboração de uma resposta ou dar determinada respostas prescritas pelo professor ou pelo livro. Nesses casos, o aluno geralmente se afasta emocionalmente da atividade e podemos pensar que ele vivencia um processo de exclusão (Alencar, 2007). Lia, no trabalho pedagógico junto ao aluno com AH/SD, não apresenta recursos, objetivos pedagógicos ou avaliação diferenciados, mas se dispõe a entrar em relação com ele, desenvolve processos comunicacionais efetivos, potencializa aquilo que motiva o aluno e demonstra capacidade de encantar-se com as descobertas dele.

\section{Considerações finais}

As principais contribuições desta pesquisa estão relacionadas a compreender o trabalho pedagógico além das estratégias instrumentais e procedimentais, bem como superar a concepção de linearidade que o envolve, dirigindo um olhar para o professor como indivíduo que, em sua ação profissional, integra processos históricos, culturais e emocionais, os quais implicam na constituição complexa de sua subjetividade. A pesquisa nos possibilitou perceber o caráter complexo da ação docente, que se fundamenta em saberes, instrumentos e, de forma muito importante, fundamenta-se em processos subjetivos.

Este estudo corrobora a importância do desenvolvimento dos recursos subjetivos necessários à prática pedagógica. Enfatiza que a ação pedagógica do professor, em sua condição de sujeito, está mediatizada em uma parte, pelo conjunto de recursos subjetivos que o caracterizam em sua constituição histórica, entre eles estão suas motivações, capacidades, representações, valores, expectativas, e por outra pelas características dos espaços sociais e interativos de onde suas ações têm lugar e o significado e o sentido que assumem para ele no vínculo inseparável e processual com sua própria ação.

A inter-relação entre a subjetividade individual e a subjetividade social nos possibilitou a compreensão das configurações subjetivas da ação da professora junto a seus alunos com AH/SD. A professora Lia, em particular, 
valoriza o aluno como sujeito e a sua capacidade de produzir ideias sobre o que estuda. Apesar de considerá-lo perfeito e completo, Lia busca ensiná-lo, do mesmo modo que a todos, e reconhece a importância do aluno na aprendizagem dos demais e no seu exercício profissional.

Em relação aos aspectos favorecedores da inclusão escolar na escola estudada, podemos citar a articulação entre a equipe de AEE, da equipe de psicólogos que atua na escola, corpo docente, gestores e famílias, em um trabalho com organicidade e colaboração, a fim de oferecer de forma complementar o atendimento aos alunos PAAE. A professora Lia, em relação à instituição, produz sentidos subjetivos de pertencimento, de valorização profissional, e sobre esse tecido subjetivo constrói uma prática que possibilita aprendizagem e expressão criativa dos alunos.

Assim, ressaltamos que os processos subjetivos, em seu caráter individual e social, são constituintes do trabalho pedagógico e a expressão do professor como sujeito pode facilitar a criação de espaços sociais propiciadores de desenvolvimento a alunos com AH/SD por possibilitar a expressão criativa e emocional destes. Os fundamentos da Teoria da Subjetividade e o método construtivo-interpretativo foram essenciais nessa construção.

\section{Referências}

AMARAL, A. L. S. N. O sentido subjetivo da aprendizagem para alunos universitários criativos. 2006. 190 f. Dissertação (Mestrado em Educação). Universidade de Brasília. Brasília, 2006.

ARROYO, M. G. Ofício de Mestre: Imagens e autoimagens. Petropólis: Vozes, 2000.

BAHIA, S.; TRINDADE, J.P. Transformar o velho em novo: a integração da criatividade na educação. In: PISKE, F.H.R.; BAHIA, S. (Orgs.) Criatividade na escola: o desenvolvimento de potencialidades, altas habilidades e talentos. Curitiba: Juruá, 2013.

FRANCO, M.A.R.S. Pedagogia: Por entre resistências e insistências. Rev. Espaço do Currículo (online), João Pessoa, v.10, n.2, p. 161-173, mai./ago. 2017.

FREITAS, S. N.; PÉREZ, A. G. P. B. Altas habilidades/superdotação: atendimento especializado. 2. ed. revista e ampliada. Marília: ABPEE, 2012. 
GARDNER, H. Inteligências Múltiplas e Teoria na Prática. Porto Alegre: Artes Médicas, 1995.

GOMES, C; GONZÁLEZ REY, F.L. Inclusão Escolar: Representações Compartilhadas de Profissionais da Educação acerca da Inclusão Escolar. Psicologia ciência e profissão, 2007, 27 (3), 406-417).

GONZÁLEZ REY, F. L. O social na psicologia e a psicologia social: a emergência do sujeito. Petrópolis: Vozes, 2004.

. La Subjetividade em uma Perspectiva Cultural-histórica: Avanzando sobre um Legado Inconcluso. CS, N ${ }^{\circ} 11$. Cali, Colombia, enero-junio, 2013.

Saúde, cultura e subjetividade: uma referência interdisciplinar / F. G. REY, BIZERRIL, J. - Brasília: UniCEUB, 2015.

GONZÁLEZ REY, F.; MITJANS MARTÍNEZ, M. El desarrollo de la subjetividad: una alternativa frente a las teorías del desarrollo psíquico. Papeles de Trabajo sobre Cultura, Educación y Desarrollo Humano, 13(2), 3-20., 2017b http://psicologia.udg.edu/PTCEDH/menu_articulos.asp

., M. Subjetividade: Teoria, Epistemologia e Método. Campinas: Alínea, 2017a. GOULART, Daniel Magalhães. Educação, saúde mental e desenvolvimento subjetivo: Da patologização da vida à ética do sujeito. Tese de Doutorado em Educação. Universidade de Brasília. Brasília, 2017.

GUENTHER, Z.C. Desenvolver capacidades e talentos: um conceito de inclusão. Petrópolis: Vozes, 2003.

MENDES, E.G.; CIA, F.; TANNÚS-VALADÃO, G. Organização e funcionamento do Atendimento Educacional Especializado. In: MENDES, E.G.; CIA, F.; TANNÚSVALADÃO, G. Inclusão Escolar em foco: Organização e Funcionamento do Atendimento Educacional Especializado. São Carlos: Marquezine \& Manzine, ABPEE, 2015. v. 4

MENDES, E. G.; CIA, F.; CABRAL, L. S. A. (Org.). Inclusão escolar e os desafios para a formação de professores em educação especial. 1. ed. São Carlos: Marquezine \& Manzine, 2015. v. 3. 530p.

MONTE, P.M. A aprendizagem do adolescente com altas habilidades: um estudo de caso na perspectiva da teoria da subjetividade. Universidade Federal do Piauí. Dissertação de Mestrado: Teresina, 2009.

MORI, N.N.R.; BRANDÃO, S.H. O atendimento em salas de recursos para alunos com altas habilidades/superdotação: o caso do Paraná. Rev. Bras. Educ. Espec., Marilia, v.15, n.3, p.485-498, 2009.

PALUDO, K. I.; LOOS-SANT'ANA, H.; SANT'ANA-LOOS, R. S. Altas habilidades / superdotação: identidade e resiliência. Curitiba: Juruá, 2014. 
PÉREZ, S. G. P. B. Mitos e crenças sobre as pessoas com altas habilidades: alguns aspectos que dificultam o seu atendimento. Revista Educação. Santa Maria, n ${ }^{0} 22$, 2003.

PÉREZ, S. G. P. B.; FREITAS, S. N. Encaminhamentos pedagógicos com alunos com altas habilidades/superdotação Educar em Revista, Curitiba, n. 41, Editora UFPR. p. 109-124, jul./set. 2011.

Do pecado de ser mulher ao medo de ser mulher com altas habilidades/superdotação. Superdotados: Trajetórias de Desenvolvimento e Realizações. Curitiba: Juruá, 2013

Políticas públicas para as Altas Habilidades/ Superdotação: incluir ainda é preciso. Revista Educação Especial, v. 27, n. 50, set./dez. 2014

RENZULLI, J.S. O que é esta coisa chamada superdotação, e como desenvolvemos? Uma retrospectiva de vinte e cinco anos. Educação (1) 75-121, 2004.

What Makes Giftedness? Reexamining A Definition. KAPAN Classic. 8 (29,) pp.81-88, 2011.

o que é esta coisa chamada superdotação, e como a desenvolvemos?uma retrospectiva de 25 anos. In: Educação e inclusão: perspectivas desafiadoras. Claus Dieter Stobäus; Juan José Mouriño. Mosquera. (Orgs.) Porto Alegre: EDIPUCRS, 2013.

A concepção de superdotação no Modelo dos Três Anéis: um modelo de desenvolvimento para a promoção da produtividade criativa. VIRGOLIM, A.M.R.; KONKIEWITZ, E.C. (Orgs.) Altas habilidades/superdotação, inteligência $e$ criatividade: uma visão multidisciplinar Campinas: Papirus, 2014.

ROSSATO, M.; MATOS, J. F.; PAULA, R.M. EDUR. A subjetividade do professor e sua expressão nas ações e relações pedagógicas. Educação em Revista. 2018; 34.

SANTOS, G. P.; CARVALHO, M.F.P. A experiência em atendimento educacional especializado no Instituto Dom Barreto: olhares sobre sua história e funcionamento na Educação Infantil e no Ensino Fundamental. In: Memórias e vivências da Psicologia Escolar: Uma prática de vanguarda no Instituto Dom Barreto. Carla Andrea Silva; Delite Conceição Rocha Barros Lemos (Orgs.) 1 ed. Teresina: Instituto Dom Barreto, 2017.

VILARONGA, C. A. R. ; MENDES, E. G.. Ensino colaborativo para o apoio à inclusão escolar: práticas colaborativas entre os professores. Rev. Bras. Estud. Pedagog. [online]. 2014, vol.95, n.239, pp.139-151.

Recebido em janeiro de 2019 Aprovado em julho de 2019 